\title{
Weathering Layer and Topographic Irregularities at the Early Stages of Seismic Data Processing Resolved with Statics Correction Method in Southern Niger Delta, Nigeria
}

\author{
Dr. Madu', Anthony Joseph Chinenyeze ${ }^{2}$ \\ Department of Physics/Geology/Geophysics, Faculty of Science and Technology, Federal University Ndufu-Alike-Ikwo, Ebonyi State
}

\begin{abstract}
The South central part of Niger delta has the terrain of high weathering thicknesses and unique profile of weathering velocities, with random spurious values. The existence of spurious values of weathering thicknesses is consequent to prolific deposition of sediments of variable lithology, densities, thicknesses and velocities. Uneven or unequal thicknesses about the creek/land boundaries, with clayey deposits on one side, and fine sand on the other exist, thus, the heterogeneity of the vadose zone. Spurious overburden of sediments in this part of the Niger delta was evident on seismic records as the introduction of spikes in the profile of weathering thicknesses. Weathering thickness "highs" tied to depositional inequality of spurious overburden and low range of weathering velocities. Deposition at many land/creek boundaries gave rise to the trend of weathering thickness and weathering velocities of uneven gradient. When the energy source was buried within the weathering depth, it came out weathered shots of low amplitude data, but it came out as strong events and good reflections when the energy source was at the depth below weathering. Rock types varied from clayey sand to sand, to silt, to shale and fine-sand sediments. There were challenging results of erratic topographic irregularities and weathering depth values resolved by statics computation or correction method which considered the heterogeneity of the weathered zone and adopted a system of slicing-off the slab of heterogeneity. An approach was the use of seismic source located at the base of the weathered layer, viz, single deep holes (SDH). That produced sharper seismic signals of good data quality which digitization and analyses yield enhanced results of improved Signal/Noise ratio. Subsequently more reliable weathering velocities (Vw) were generated and similarly more accurate computation of the thickness of the weathered layer or the low-velocity-layer (LVL). The challenge was resolved by use of statics correction which effects automated replacement of the heterogeneous layer with underlying layer attributes / consolidated velocity. It produced weathering thicknesses ranging from $5.1 \mathrm{~m}$ to $33 \mathrm{~m}$ and off-mark spurious patches $37 \mathrm{~m}$ to $41 \mathrm{~m}$ while the weathering velocities measured $410 \mathrm{~m} / \mathrm{sec}$ to $550 \mathrm{~m} / \mathrm{sec}$. Off-mark values of weathering velocities ranged from $390 \mathrm{~m} / \mathrm{sec}$ to $400 \mathrm{~m} / \mathrm{sec}$. Good seismic signals of the refractor or consolidated layer yielded velocity values that ranged from $1667 \mathrm{~m} / \mathrm{sec}$ to $1750 \mathrm{~m} / \mathrm{sec}$.
\end{abstract}

Keywords: weathering thickness, weathering velocities, vadose zone, static correction, depositional inequality and overburden.

\section{Introduction}

Seismic investigation in the Southern part of the Niger delta is based on the principle of wave propagation using energy source generated by spiking charges of dynamite and detonators buried at determined depths (ds). But the travel pattern of the waves through the earth medium varies from the near surface, which includes the loose and unconsolidated vadose zone (LVL) in weathering, and that of underlying consolidated layer, when the depth of charge is below or at the base of weathered layer. The vadose zone which is characterized by loose sediments and less compacted and of lesser density $\mathrm{Q} 1$ than the underlying consolidated sediments of higher density $\mathrm{Q}_{2}$.

Initial level of low range of weathering velocities $\mathrm{Vw}$ or Vo, and elevations of various stations were evaluated, and corrections were computed and applied to removed the effect of sedimentary inhomogeneous, topographic materials and various weathering thicknesses which were responsible for the difference in density relative to that of the consolidated layer. Variables of near surface problems in the early stages of seismic data processing were increased when the energy sources of seismic waves increased to include buried charges of dynamite and detonators at designated shot depths (ds), and a further mixture of buried charges at depths (ds) and airgun shots in creeks/rivers or transition zone. The mixture of a near earth's surface based energy sources and buried sources at shallow depths, and Single deep holes (SDHs) sources at depths below weathering (ds $>$ or $=d w)$, was tantamount to unique problems, which were resolved by the Statics Corrections, in addition to the total Geophone correction for the receiver stations.

Shallow refraction surveys (LVL) stand out as the conventional method for determining the near-surface characteristics (Dubrin, 1983). For detailed and comparative investigations of the near-surface characteristics the uphole method is adopted (Telford, etal, 1976). Lithologic variations, velocities and weathering depths of the nearsurface are more accurately determined by use of upholes, than refraction surveys LVL (Marsden, 1993). Researches already conducted on near-surface zone in the Niger delta Nigeria include (Uko etal 1992) which determined the weathering structure of the southeast central portion of the Niger delta. The result showed that the Southeastern region had a variable weathering thickness ranging from $2.9 \mathrm{~m}$ to $35.5 \mathrm{~m}$ with an average value of $20.0 \mathrm{~m}$. The average weathering velocity and the refractor velocities as investigated by Eze, etal (2003) by LVL refractor survey ranged from 400 to $500 \mathrm{~m} / \mathrm{s}$ and $1700 \mathrm{~m} / \mathrm{s}$ to $1732 \mathrm{~m} / \mathrm{s}$ respectively.

The first breaks were picked and statics corrections were generated on the arrival times using factors computed from 


\section{International Journal of Science and Research (IJSR) \\ ISSN (Online): 2319-7064 \\ Index Copernicus Value (2013): 6.14 | Impact Factor (2015): 6.391}

the weathering velocities and refractor velocities worked out from the derivations of figures 2 and 3 . The first breaks stand as 2-way travel times, which are considered and halfed in practice. Travel time represents the ray-path and return journey of the wave from the source point to the jug or geophone station, represents delay due to the topographic irregularities or inhomogeneities which the static correction takes care of.

\section{Geological Setting}

The structural features of the Niger delta reveal sediments of Benin formation overlying the reservoir Agbada formation of characteristic growth faults and roll over anticline of sand and shale sequences. The latter overlies the Akata Shale of diapriric behavior. The seismic investigation aims at delineating the fracture patterns and structural traps with the faulting of the reservoir Agbada formation, which are favorable to hydrocarbon accumulation.

The study area is located in the South central part of the Niger Delta (Fig 1.0). It is bounded by latitudes 04deg and 06degN and longitudes 06deg E and 07deg E.

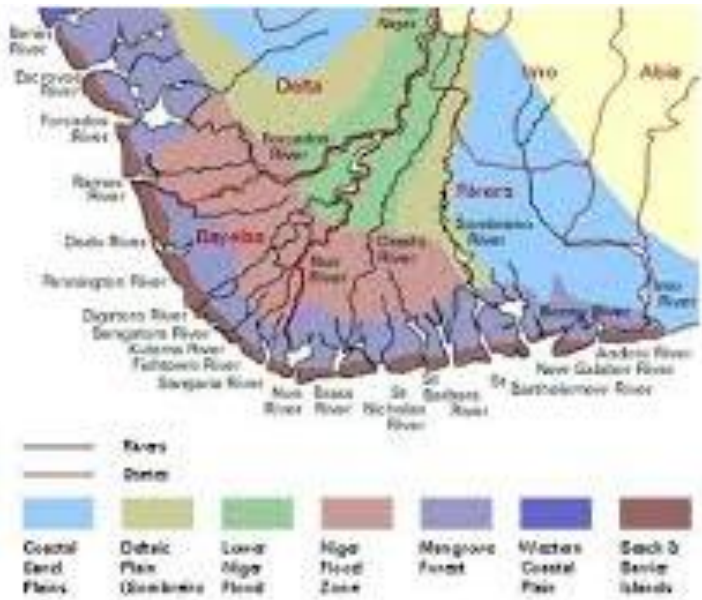

Figure 1: Map of Niger delta

The Niger delta is made up of three sedimentary formations, namely the Benin formation, the Agbada formation and the Akata formation. These date from Eocene to Pliocene Hospers (1965). The Benin formation consists of coarse grained, gravelly sandstone, with minor intercalations of shale. It is a continental deposit of Miocene to recent, with thickness up to $1800 \mathrm{~m}$. It overlies the Agbada formation which consists of alternating sequences of sandstone and shale, of fluviomarine paleogeography. It is of Eocene to Pliocene age. The sediments consists of sands, sandstone and marine shale, which make up the Agbada formation build up to a large amount of sedimentary thickness up to $4600 \mathrm{~m}$, with some characteristic pollen fossils. The large amount of sedimentary thickness yielded to gravitational faulting resulting to growth faults and roll over anticlines, which are favourable to hydrocarbon accumulation (Kogbe, 1976). The structural developments in the formation provide suitable traps for hydrocarbon. The Akata formation consists of shale with local interbedding of sands and siltstone, with special diapiric behavior.

The area of New Calabar River and adjoining flood plain make up elevation plain and swampy terrain of this Southern Niger Delta. There are characteristic meanderings and oxbow lakes in the low elevation terrain. The region of low elevation within the flood plain and westward was underlain by compacted clay sediment especially as revealed by uphole lithologic logs consisting of clay, clay sand, fine to coarse grained sand, and gravel layer. (Aseez 1976).

\section{Methodology}

The data acquisition was conducted using the Mc Seis Oyo 24 channel instrument characterized system. It was used for carrying out shallow refraction survey (LVL) and uphole survey for more precise details of the weathered layer (or Vadose zone) to obtain weathering velocities and thicknesses, and refractor velocity range.

The line equipment consisted of 24 jugs or geophones with good coupling into the ground, and the interlinking telemetry cables for relay of signals from the receiver stations to the McSeis Instrument location. The energy source that generated the wave propagation was majorly small charge of 200grams of dynamite and accompanying lead-detonator buried in drilled holes of stipulated depth, as depth of shot (ds). The waves propagated into the subsurface are refracted (or reflected) back to the surface whenever it encountered impedance or a layer of strong density contrast.

The method of computation was derived from the equations worked out from the diagrams in Figures 2a, 2, and 3 below.

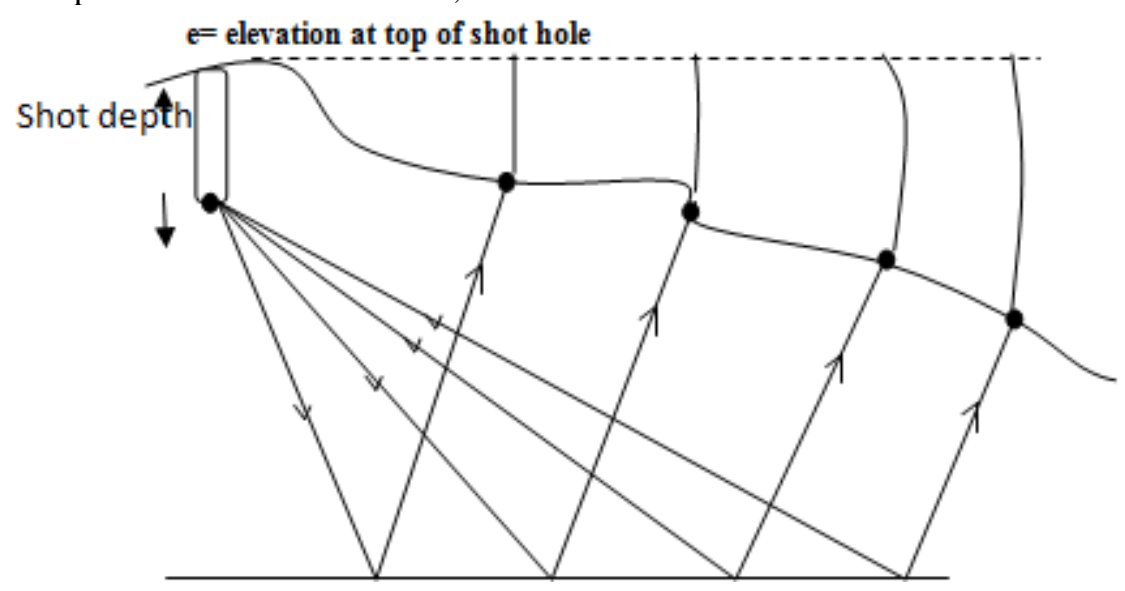

Figure 2a: The sources of irregularities are varying surface elevations and weathering depths.

\section{Volume 5 Issue 4, April 2016}




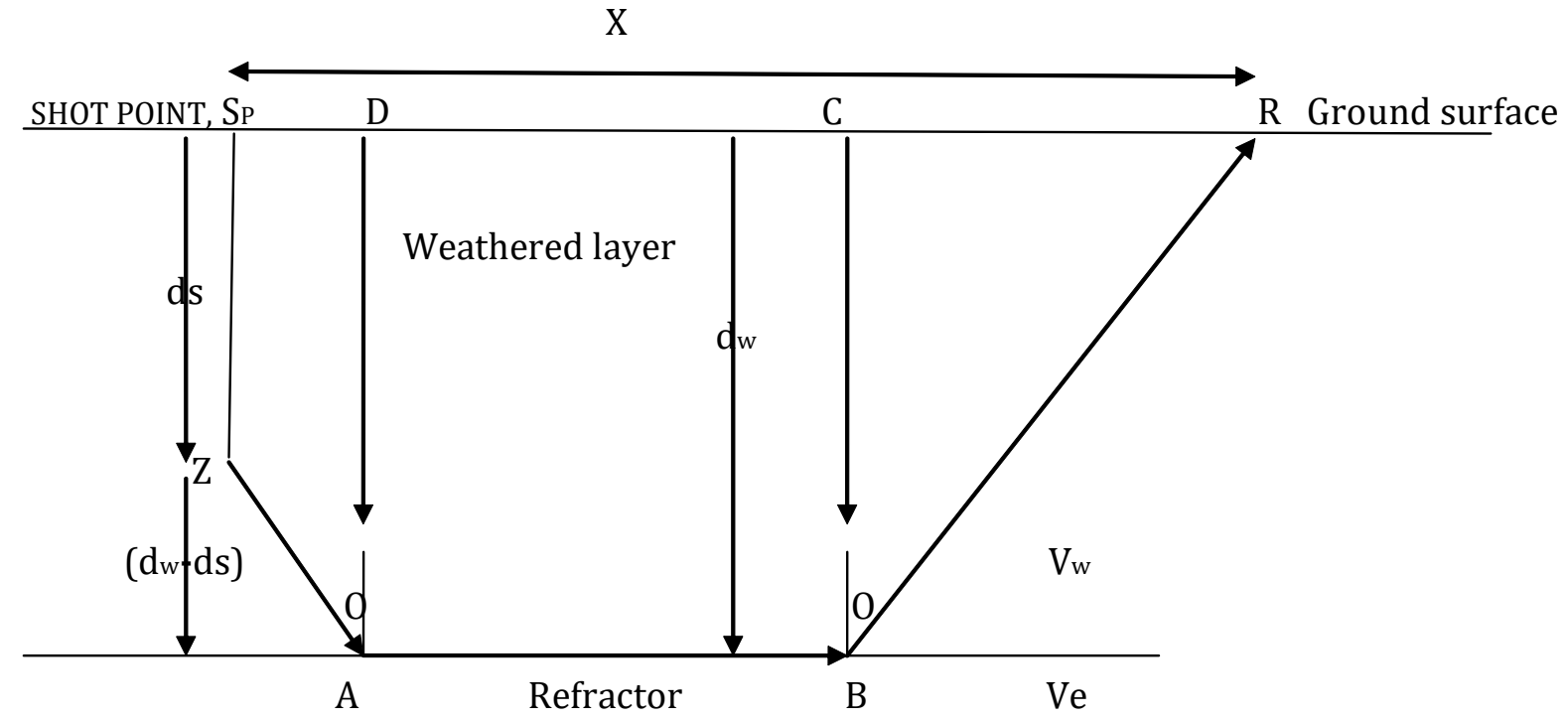

Figure 2: Illustration of Dynamite Shot in weathered layer, $\mathrm{ds}<\mathrm{dw}$.

Where $\mathrm{Vw}_{\mathrm{w}}=$ Velocity in the weathered layer, while $\mathrm{Ve}=$ Velocity in the consolidated layer.

At critical angle of incidence, the wave travelling along the boundary has the velocity of the lower layer.

\section{Static Corrections Employed in Solving Weathering and Topographic Irregularities in Seismic data Processing:}

Considering a Scenario of Refraction in a Single Layer Interface:

The field conditions in seismic data acquisition accommodates shot points in weathering, together with shots taken below the weathering or at the base of weathered layer.

\section{Cases of Travel Time Equations}

A. Scenario of shallow shots taken at shot depth (ds) within the weathered layer where $\mathrm{ds}<\mathrm{dw}$.

Where $\mathrm{dw}=$ the thickness of the weathered layer and Ds = depth of shot.

Consider the total travel time $\mathrm{T}$ between the shot point $\mathrm{S}$ of depth ds, with the charge or energy source at $\mathrm{Z}$ and the receiver at $R$.

$$
\begin{array}{r}
\mathrm{T}=T_{Z A}+T_{A B}+T_{B R} \cdots \\
T=\frac{Z A}{V w}+\frac{A B}{V e}+\frac{B R}{V w} \\
T=\frac{d_{w}-d_{s}}{V_{w} \operatorname{Cos} \theta}+\frac{A B}{V_{e}}+\frac{d w}{V w \operatorname{Cos} \theta}
\end{array}
$$

Where $\mathrm{Vw}=$ Velocity in the weathered layer, while $\mathrm{Ve}=$ Velocity in the consolidated layer.

At critical angle of incidence, the wave travelling along the boundary has the velocity of the lower layer.
$\operatorname{Sin} \theta_{c}=\frac{V_{1}}{V_{2}}$

Where the $1^{\text {st }}$ refraction sets at the critical distance, and $h=d w \tan \theta$

Where $\mathrm{AB}=\mathrm{X}-(\mathrm{SO}+\mathrm{QR})$

$S O=\frac{S O}{d w-d s}=\tan \theta$,

ThusSP $=d w-d s \tan \theta$

$T=\frac{d w-d s}{V w \operatorname{Cos} \theta}+\frac{X-(] d w-d s] \tan \theta)}{V e}+\frac{d w \tan \theta}{V e}+\frac{d w}{V w \operatorname{Coc} \theta}$ --Equ-4

Hints,

$$
\begin{aligned}
& \frac{h}{d w}=\tan \theta \\
& h=\frac{d w \tan \theta}{1} \\
& T=\frac{d w-d s}{V w \operatorname{Cos} \theta}+\frac{X-(2 d w \tan \theta-d s \tan \theta)}{V e}+\frac{d w}{V w \operatorname{Cos} \theta} \\
& T=\frac{X}{V e}+\frac{2 d w}{\operatorname{Cos} \theta}\left(\frac{1}{V e}-\frac{V w}{V e^{2}}\right)-\frac{d s}{\operatorname{Cos} \theta}\left[\frac{1}{V w}-\frac{V w}{V e^{2}}\right]
\end{aligned}
$$
Hint,

Since, $\operatorname{Cos}^{2} \theta=1-\operatorname{Sin}^{2} \theta$

$T=\frac{X}{V e}+\frac{2 d w\left(V e^{2}-V w^{2}\right)^{1 / 2}}{V e V w}-\frac{d s\left(V e^{2}-V w^{2}\right)^{1 / 2}}{V e V w}$-----Equ-7

To obtain weathering thickness, set the offset distance to zero i.e. $X=0$. And the Total time becomes the intercept time, Ti.

Thus Equ-7 translates to,

$$
T i=\frac{2 d w\left(V e^{2}-V w^{2}\right)^{1 / 2}}{V e V w}-\frac{d s\left(V e^{2}-V w^{2}\right)^{1 / 2}}{V e V w} \ldots . . \text { Equ-8 }
$$

Multiplying through by the factor below, 


\section{International Journal of Science and Research (IJSR) \\ ISSN (Online): 2319-7064}

Index Copernicus Value (2013): 6.14 | Impact Factor (2015): 6.391

$$
\frac{V e V w}{2\left(V e^{2}-V w^{2}\right)^{1 / 2}} \quad d w=\frac{T i}{2} \frac{V e V w}{\left(V e^{2}-V w^{2}\right)^{1 / 2}}+\frac{d s}{2}
$$

$T i=\frac{2 d w\left(V e^{2}-V w^{2}\right)^{1 / 2}}{V e V w}-\frac{d s\left(V e^{2}-V w^{2}\right)^{1 / 2}}{V e V w}$

From Equ-8 above, the Statics correction can be obtained, as direct equivalent of the intercept time $\mathrm{Ti}$, in milliseconds.

$\frac{V e V w}{2\left(V e^{2}-V w^{2}\right)^{1 / 2}}$

Scenario of Single Deep Hole Source, - Shooting Below Weathering Thickness

By rearrangement, the weathering thickness becomes,

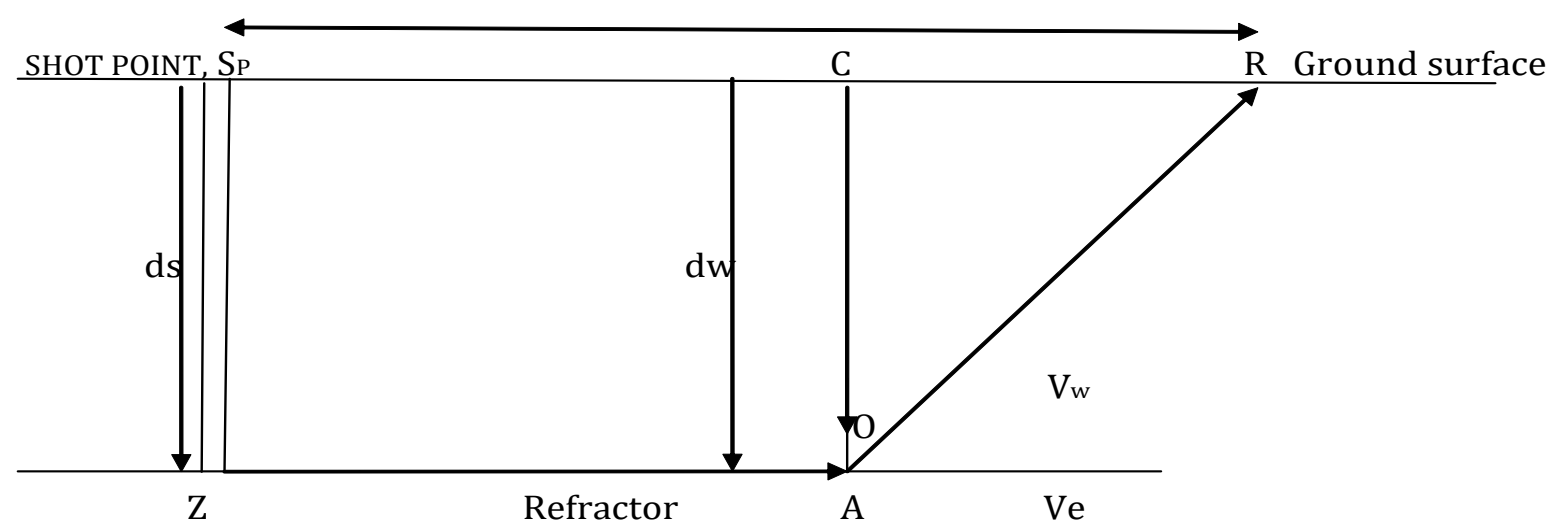

Figure 3 Dynamite Shot taken at the base of weathering thus, in the refractor layer, $\mathrm{ds}=\mathrm{dw}$.

The total travel time in this case can be expressed as,

$$
\begin{aligned}
& \mathrm{T}=\mathrm{TZA}+\mathrm{TAR} \\
& =\frac{Z A}{V e}+\frac{A R}{V w}
\end{aligned}
$$

$$
\begin{aligned}
& =\frac{X-d w \tan \theta}{V w}+\frac{d w}{V w \operatorname{Cos} \theta} \\
\mathrm{T}= & \frac{X \operatorname{Cos} \theta-d w \sin \theta}{V e \operatorname{Cos} \theta}+\frac{d w}{V w \operatorname{Cos} \theta} \\
& =\frac{X}{V e \operatorname{Cos} \theta}+\frac{d w\left(V_{e}^{2}-V_{w}{ }^{2}\right)^{1 / 2}}{V e V w}
\end{aligned}
$$

Thus,

$$
T i=\frac{d w\left(V e^{2}-V w^{2}\right)^{1 / 2}}{V e V w}
$$

Thus, the weathering thickness can be deduced as

$$
d w=\frac{T i V e}{\operatorname{Cos} \theta}
$$

\section{Result and Analysis}

At zero offset distance, $\mathrm{X}=0, \mathrm{~T}=\mathrm{Ti}$

Table 1: Location and Analyses/Interpretation of Uphole Points And LVL'S

\begin{tabular}{|c|c|c|c|c|c|c|c|c|}
\hline S/N & Easting & Northing & Elevation & $\begin{array}{c}\text { VEL. OF WEATHERED LAYER } \\
\text { Vw(m/s) }\end{array}$ & $\begin{array}{c}\text { VEL V1 } \\
(\mathrm{m} / \mathrm{s})\end{array}$ & Ti1(m) & Ti2(m) & Dw(m) \\
\hline 1 & 523349.79 & 72855.89 & 2.71 & 544 & 1671 & 4.1 & 20.2 & 24.3 \\
\hline 2 & 523351.59 & 72855.80 & 2.53 & 310 & 1720 & 5.5 & 14.6 & 20.1 \\
\hline 3 & 523352.79 & 72855.89 & 2.52 & 897 & 1600 & 4.2 & & 4,2 \\
\hline 4 & 523389.50 & 72865.69 & 2.21 & 850 & 1715 & 3.7 & 22.2 & 25.9 \\
\hline 5 & 523489.60 & 72885.79 & 1.90 & 750 & 1725 & 5.2 & 18.9 & 24.1 \\
\hline 6 & 523519.78 & 72899.60 & 1.80 & 650 & 1750 & 5.5 & 22.5 & 28.0 \\
\hline
\end{tabular}

\section{Discussion}

When the energy source is buried within the weathering thickness, it comes out a weathered shot of low amplitude data, but yields strong events and good reflections when the source is below weathering, as in Fig. 3. Time equivalent of the $\mathrm{dw}$ (in msec.) in all the channels or stations upon statics correction is sliced-off from the overall time signal represented at different channels or traces. That was equivalent to carrying out a downward continuation on the 


\section{International Journal of Science and Research (IJSR) \\ ISSN (Online): 2319-7064 \\ Index Copernicus Value (2013): 6.14 | Impact Factor (2015): 6.391}

time-series in which the weathering layer was removed with respect to time (in milliseconds) down to the datum. That will present the earth being investigated as a slab of consolidated sediments, with its surface at the datum, and the weathering layer irregularities sliced-off.

Having considered the near-surface problems due to seismic wave path through the weathered zone, the remaining effect falls on irregularities due to topographic build-up or the earth's geomorphology. The latter was corrected for by measuring the Elevation, and application of elevation correction, its effect was removed by a downward continuation to the datum with medium velocity as the refractor or consolidated velocity.

\section{Conclusion}

The problem of weathering thickness variations in the lower Southern Niger delta, where topographic or elevation effect was corrected to the datum, which however tied with prolific sedimentary depositions or piling, and spurious off-mark values at certain creek boundaries, corrected by calibration of such weathering layers by uphole determination of thicknesses dw, and weathering velocities Vw. These parameters in conjunction with the refractor velocities were used to compute correction factors or constants which were applied to all the channels or trace values or signals to effect the static corrections. Thus, the effect of non-homogeneities of the weathered layer, the effect of irregular topography and differences in elevation were thus, corrected and compensated for in the statics correction to bring the surface to the datum.

\section{References}

[1] Aseez L.O. (1976). Review of Stratigraphy, sedimentation, and structure of the Niger Delta. In: Kogbe C.A. (ed). Geology of Nigeria. Elizabethan Press, Lagos, Nigeria. Pp 259-272.

[2] Brain, B. (2001). Seismic Studies to Contribute to Decision on Proposed Landfill. Oversight News, Newsletter of the Commonwealth's Environmental Oversight of the Paducah Gaseous Diffusion Plant, 9, No. 32001.

[3] Dobrin, M. B. (1983). Introduction to Geophysical Prospecting. Mc Graw-Hill Book Co., London.3ad Ed., PP. 294-300;307-310.

[4] Enikanselu, P.A (2008). Geophysical Seismic Refraction and Uphole Survey Analysis of Weathered Layer Characterstics in the " Mono" Field, South-Western Niger Delta, Nigeria. Pacific Journal of Science and Technology. 9 (2) 537-546

[5] Eze, C. L., Okwueze, E. E. and Uko, E. D. (2003). The velocity- thickness characteristics of the mangrove swamp low velocity layer (LVL) South central Niger Delta, Vol. 9, No. \#, p. 369-374.

[6] Marsden, D., (1993) Static correction. A review, The Leading Egde.

[7] Telford, W.M., Geldart, L. P., Sheriff, P. E. and Keys, D.A. (1976). Applied Geophysics. Cambridge University Press, London, Pp. 271; 281-284
[8] Uko, E.D., Ekine,A.S., Ebeniro, J. O. and Ofoegbu, C. O. (1992). Weathering structure of the East Central Niger Delta, Nigeria, Geophysics 57 (9): 1228-1233. 